\title{
STRATEGI MENGATASI PENYEBAB SURGING PADA MESIN DIESEL PENGGERAK UTAMA DI MT. ONTARI
}

\author{
Tazani, A. A $\mathbf{A}^{1}$, Santiko, $\mathbf{T}^{2}$, Tjahjono, A. $\mathbf{A}^{3}$, Sapan, $\mathbf{Y}^{4}$. \\ ${ }^{1}$ Politeknik Ilmu Pelayaran: Teknika, Indonesia \\ Email: 'zany120594@gmail.com \\ ${ }^{2}$ Politeknik Ilmu Pelayaran: Teknika, Indonesia \\ Email: ${ }^{2}$ toni34.santiko@gmail.com \\ ${ }^{3}$ Politeknik Ilmu Pelayaran: Teknika, Indonesia \\ Email: 3a_agus_tjahjono70@yahoo.com \\ ${ }^{4}$ Politeknik Ilmu Pelayaran: Nautika, Indonesia \\ Email: ${ }^{4}$ yustinsapan133@gmail.com
}

\begin{abstract}
ABSTRAK
Turbocharger is a component to increase the amount of air that enters the cylinder by using exhaust gas energy. The instability of exhaust gas pressure causes a surging in the turbocharger which affect the performance of Main Diesel Engine, such as piston rings and turbocharger blades broken that disturb ship operations. The research method used in this research is descriptive qualitative method. Data analysis techniques use the SWOT method to analyze the factors that cause surging of the Main Diesel Engine and the efforts made to overcome the factors associated with strengthening, weakness, opportunities, and protection. Based on the results of research conducted by researchers, is caused by two factors, first the escape of compression during combustion due to oversize cylinder liner and second is spare parts of the main engine supply on the ship is hampered. To fixes the factors that can be done using cylinder liner that has been oversized, reducing the rotation of the main engine so that the exhaust gas is more stable, reducing the consumption of cylinder oil to reduce sludge in the scavenging air chamber, using a blower to be manual to increase the scavenging air to normal pressure during the engine operation, reconditioning the spare parts of Main engines such as crown pistons and piston rings by repairing so that they can be used again temporarily waiting for parts to arrive on board, and buy spare parts with spare money on board that are lightweight and inexpensive for maintenance and repair of main engine.
\end{abstract}

Keywords: surging, turbocharger, SWOT

\section{PENDAHULUAN}

Turbocharger adalah komponen yang berupa kompresor dalam mesin pembakaran dalam untuk meningkatkan keluaran tenaga mesin dengan meningkatkan massa oksigen yang memasuki mesin (Mahadi, 2010). Menurut Endrodi (2004: 24) "Pada mesin diesel dipasang turbocharger bertujuan untuk memasukan udara sebanyak-banyaknya kedalam silinder dengan tekanan lebih dari 1 atmosfer". Turbocharger merupakan suatu alat yang berfungsi untuk menghasilkan tekanan udara di atas 1 atmosfer, dimana maksud dan tujuannya adalah supaya dalam proses pembakaran bahan bakar dalam silinder tersedia oksigen yang cukup, sehingga 
akan terjadi pembakaran yang sempurna dan menghasilkan daya yang lebih besar pada motor dibanding tanpa menggunakan turbocharger.

Dalam kenyataannya, mesin diesel penggerak utama di MT. Ontari sering mengalami gangguan yaitu surging selama Oktober-Desember 2016. Apabila hal ini tidak segera diatasi, maka akan mempengaruhi kondisi turbocharger dan Mesin Induk Penggerak Utama, seperti rusaknya sudu-sudu turbocharger, kinerja Mesin Diesel Penggerak Utama terganggu, piston ring sering patah sehingga dapat mengganggu operasional kapal dan menyebabkan keterlambatan kapal tiba di pelabuhan tujuan.

Dengan mencermati latar belakang dan judul yang sudah ada, peneliti merumuskan rumusan masalah yaitu, apakah faktor penyebab terjadinya surging Mesin Diesel Penggerak Utama dan bagaimana upaya mengatasi faktor-faktor penyebab surging Mesin Diesel Penggerak Utama.

Menurut Sukoco, M.pd. dan Zainal Arifin, M.T (2013: 127-128) turbocharger adalah sebuah komponen untuk menambah jumlah udara yang masuk kedalam silinder dengan memanfaatkan energi gas buang. Turbocharger merupakan peralatan untuk mengubah sistem pemasukan udara secara alami dengan sistem paksa. Turbocharger juga di pasang sebagai usaha untuk mengurangi kerugian pembuangan yang cukup besar dari gas buang yang melewati saluran buang. Mesin yang menggunakan turbocharger, gas buang yang keluar dimanfaatkan untuk menggerakan turbin dan menggerakan kompressor. Kompressor tersebut memompa udara masuk ke dalam silinder, sehingga menaikan tekanan dan jumlah udara masuk ke dalam silinder. Dengan demikian, jumlah udara yang di masukan ke dalam silinder dapat diperbanyak sehingga daya mesin dapat menjadi lebih besar.

Menurut Endrodi (2004: 24) turbocharger sendiri memiliki 2 bagian penting yaitu:

a. Bagian turbin side, berhubungan dengan exhaust gas dari mesin induk, exhaust gas yang keluar dari mesin induk melalui manifold selanjutnya dilewatkan menuju turbin side dan dibawa ke economizer yang akhirnya keluar melalui cerobong. Daya tekanexhaust gas inilah yang digunakan sebagai sumber penggerak utama turbin side untuk memutar sudusudu.

b. Bagian blower side, berfungsi menghisap udara luar untuk menyuplai udara bersih yang dipakai dalam proses pembakaran didalam silinder. Blower side berputar karena satu poros dengan poros pada turbin side. Saat tekanan exhaust gas memutar turbin side, maka blower side juga ikut berputar dan menghisap udara dari luar untuk diteruskan menuju silinder melalui intercooler dan scaving air trunk. 
Menurut Dough Woodyard (7: 126) surging merupakan kejadian dimana turbocharger mengalami overrunning lalu berhenti seketika, kemudian berputar dengan normal kembali, tidak berapa lama overrunning kembali. Saat akan terjadi surging, kompresor akan berputar dengan kecepatan di atas kecepatan normalnya (overrunning), hal ini terjadi karena kompresor tidak menghasilkan udara bertekanan yang disuplai ke dalam Mesin Induk, sehingga seolaholah turbocharger berputar tanpa beban.

Surging terjadi karena suatu getaran frekuansi tinggi dari impeller (rotor) yang berputar pada keadaan tertentu dan kompresor udara harus menyalurkan udara dengan tekanan tertentu sesuai dengan putaran turbin dan karena suatu sebab tekanan udara di dalam ruang pembilasan (scavenging air trunk) sama atau lebih tinggi dibandingkan dengan tekanan udara yang dihasilkan oleh blower kompresor, maka ada kecenderungan tekanan udara membalik arah melawan sudu-sudu blower yang berputar.

Salah satu penyebab surging pada turbocharger disebabkan karena ketidakmampuan difuser untuk menghasilkan tekanan yang cukup untuk mendorong udara menuju ruang bakar. Penyebab surging tidak selalu berasal dari turbocharger, mengingat bahwa turbocahrger dengan Mesin Induk adalah pasangan yang saling berkaitan dan memiliki interdependensi yang kuat. Akan kita lihat dari tiga sudut pandang penyebab surging yaitu Mesin Induk, turbocharger, dan lingkungan operasi. Surging bisa disebabkan oleh kualitas pembakaran Mesin Induk yang tidak sempurna.

Pembakaran di dalam Mesin Induk terjadi karena bahan bakar disemprotkan ke dalam silinder yang berisi tekanan udara yang sangat tinggi dan memiliki temperatur yang tinggi sebagai akibat dari proses kompresi. Jika pada saat kompresi tekanan udara yang dibutuhkan untuk pembakaran kurang, maka pembakaran yang berlangsung di dalam silinder menjadi tidak sempurna dan mengganggu pengoperasian dari turbocharger.

Udara bilas (scaving air) pada main engine digunakan sebagai sumber udara untuk dikompresikan saat melakukan pembakaran pada silinder main engine. Udara bilas juga berfungsi untuk membilas sisa pembakaran dari silinder menuju exhaust manifold untuk membersihkan gas-gas sisa pembakaran di dalam combustion chamber. Udara bilas bertekanan tersebut dihasilkan dari putaran blower pada turbochager saat mesin sedang beroperasi dan dibantu auxiliary blower saat sedang melaksanakan manouver ataupun saat putaran main engine kurang dari $80 \mathrm{rpm}$ (sesuai instructionand manual book B\&W 6L42MC).

Turbocharger dalam menghasilkan udara tekan harus di atas tekanan 1 atm serta dalam keadaan dingin. Jika udara dingin, maka udara tersebut menjadi padat dan berat. Sehingga, 
molekul oksigennya (O2) bertambah banyak. Molekul-molekul oksigen yang banyak ini akan menimbulkan pembakaran yang sempurna, sehingga daya output mesin dapat lebih maksimal. Jika hasil udara tekan yang di suplai oleh blower berkurang maka otomatis jumlah udara murni yang masuk ke dalam silinder juga pasti berkurang. Keadaan ini akan menyebabkan proses pembakaran yang terjadi di dalam silinder berlangsung tidak sempurna dan daya yang dihasilkan oleh Mesin Induk tidak maksimal, serta pembilasan gas sisa pembakaran yang terjadi juga tidak dapat berlangsung secara maksimal, sehingga banyak kotoran sisa akan terkumpul di dalam ruang pembakaran.

\section{METODE PENELITIAN}

\section{A. Jenis Data}

Jenis data yang digunakan dalam penelitian ini dibedakan menjadi dua, yaitu:

1. Data Primer

Data ini diperoleh dengan melaksanakan observasi langsung ke lokasi penelitian, dengan tujuan memperoleh data yang konkrit. Data primer yang diperoleh dari hasil wawancara kepada para Masinis yaitu tentang permasalahan surging Mesin Diesel Penggerak Utama di atas kapal serta cara mengatasinya.

2. Data Sekunder

Data sekunder diperoleh dari kajian pustaka yang diambil dari buku yang berkaitan dengan surging. Data dari buku tersebut dijadikan pembanding dan sumber untuk memperkuat jawaban dalam pemecahan masalah. Sumber sekunder digunakan untuk mendukung atau melengkapi data yang sudah didapatkan secara langsung. Beberapa data sekunder yang digunakan adalah Instruction Manual Book Mesin Diesel Penggerak Utama, Monthlyreport Planning Maintenance Systemyang terdapat di MT. Ontari, dan kuisioner yang disebarkan kepada Pasis ATT II sebagai data pendukung.

\section{B. Metode Pengumpulan Data}

Dalam penelitian ini Peneliti menggunakan beberapa teknik pengumpulan data yang peneliti anggap tepat, antara lain:

1. Metode Observasi (Pengamatan)

Dalam hal ini Peneliti akan melaksanakan penelitian di MT. Ontari, tentang surging Mesin Diesel Penggerak Utama pada periode 13 Desember 2015 sampai dengan 04 Januari 2017.

2. Metode Wawancara 
Dalam metode wawancara ini, peneliti menanyakan langsung kepada masinis maupun Kepala Kamar Mesin di MT. Ontari mengenai penyebab surging sebagai data pendukung dalam penelitian ini. Proses analisis data dari hasil wawancara ini dilakukan secara terus menerus selama proses penelitian berlangsung. Dengan proses semacam ini akan dapat diperoleh hasil yang akurat.

3. Kuisioner

Kuesioner dilakukan dengan cara menyebarkan seperangkat daftar pertanyaan tertulis kepada responden yang menjadi anggota sampel penelitian yaitu Pasis ATT II di PIP Semarang.

4. Studi Pustaka

Dalam hal ini studi pustaka yang dilakukan peneliti yaitu menghimpun informasi dari buku manual, buku-buku mengenai surging dan mesin diesel, karya ilmiah tentang surging dan mesin diesel, serta dari internet.

\section{Teknik Analisis Data}

Teknik analisis data yang akan dipakai oleh peneliti yaitu dengan menggunakan analisis SWOT untuk merumuskan strategi yang akan diambil. Strategi tersebut antara lain:

1. Strategi optimalkan kekuatan untuk memanfaatkan peluang (Strategi Ekspansi/ pertumbuhan),

2. Strategi menggunakan kekuatan untuk mencegah dan mengatasi ancaman (Strategi Diversifikasi),

3. Strategi mengurangi kelemahan dengan memanfaatkan peluang (Strategi Aliansi/ stabilitas),

4. Strategi mengurangi kelemahan untuk mengatasi ancaman (Strategi Defensif).

Pada pengolahan data menggunakan metode SWOT dilakukan dengan memberikan penilaian-penilaian faktor menggunakan tabel-tabel untuk menentukan Faktor Kunci Keberhasilan (FKK) seperti yang dituliskan pada modul LAN (2018) [7], yaitu: Bobot Faktor (BF), Nilai Dukungan faktor (ND), Nilai Relatif Keterkaitan faktor (NRK), Total Bobot Nilai (TNB), serta Peta Kuadran Strategi.

\section{HASIL DAN PEMBAHASAN}

\section{A. Gambaran Umum}

1. Objek Penelitian 
a. Gambaran umum tentang mesin diesel penggerak utama.

Adapun spesifikasi dari mesin diesel penggerak utama (main engine) MT. Ontari adalah seagai berikut:

$\begin{array}{lll}\text { Nama } & : & \text { Main Engine } \\ \text { Type } & : & \text { Mitsui ManB\&W 6L42MC } \\ \text { Maker } & : & \text { Onomichi Dockyard } \\ \text { MCO / CSO } & : & 7650 \text { PS x 175 RPM / 6690 PS x 159,9 RPM } \\ \text { Cyl. Number } & : & 6 \text { cylinder } \\ \text { Diameter silinder } & \text { : } & 420 \mathrm{~mm} \\ \text { Langkah piston } & : & 1360 \mathrm{~mm} \\ \text { Pmax / Pma } & : & 140 \mathrm{bar} / 17 \mathrm{bar}\end{array}$

b. Turbocharger

Spesifikasi dari turbocharger yang digunakan pada Main Engine di kapal MT. Ontari adalah sebagai berikut:

$\begin{array}{lll}\text { Turbocharger } & : & \text { VTR-454-32 with oil cooled system } \\ \text { System } & : & \text { Constant pressure system } \\ \text { RPM } & : & 14000 \mathrm{rpm} \\ \text { Pelumasan } & : & \text { Oil cooled system } \\ \text { Maker } & : & \text { Mitsui MAN B\& }\end{array}$

\section{B. Analisis Hasil Pembahasan}

Analisis dan pendekatan masalah yang Peneliti kemukakan adalah sebagai berikut:

1. Faktor-faktor apakah yang menyebabkan surging Mesin Diesel Penggerak Utama:

a. Lolosnya kompresi pada saat pembakaran.

Dari hasil observasi, wawancara, dan studi pustaka yang peneliti lakukan, pada pelayaran dari Balongan menuju Balikpapan pada tanggal 8 Oktober 2016 terjadi surging, sehingga kinerja Mesin Induk terganggu. Hal ini disebabkan karena tekanan udara bilas berkurang dan pembakaran yang tidak sempurna. Dari observasi peneliti saat melakukan penelitian di atas kapal MT. Ontari, pembakaran yang tidak sempurna dan tekanan udara bilas yang turun dibawah normal disebabkan karena pada kondisi di kapal MT. Ontari, cylinder liner sudah oversize melebihi batas dari ketentuan. Ukuran cylinder liner normal yaitu $420 \mathrm{~mm}$ dengan toleransi $0.4-0.8 \%$ atau sekitar $421.68 \mathrm{~mm}-423.36 \mathrm{~mm}$. 
Namun pada nyatanya ukuran diameter cylinder liner yang dilakukan pengukuran mendapatkan hasil di luar batas toleransi yang diijinkan.

Gambar 1. Posisi

Tabel 1. Hasil Pengukuran Cylinder Liner

\begin{tabular}{c|ccccccccc}
\hline $\begin{array}{c}\text { Cycl } \\
\text { No. }\end{array}$ & Position & D1 & D2 & D3 & D4 & D5 & D6 & D7 & D8 \\
\hline 1 & X & 424.06 & 424.43 & 423.78 & 423.09 & 420.95 & 421.12 & 421.15 & 420.95 \\
& Y & 424.45 & 424.56 & 423.82 & 423.25 & 420.77 & 420.42 & 420.25 & 420.25 \\
2 & X & 423.80 & 424.12 & 423.35 & 422.75 & 420.95 & 421.05 & 421.10 & 420.83 \\
& Y & 424.17 & 424.35 & 423.60 & 422.95 & 420.65 & 410.75 & 420.60 & 420.60 \\
3 & X & 424.25 & 424.27 & 423.96 & 423.17 & 421 & 421.12 & 421.15 & 421.15 \\
& Y & 424.7 & 424.99 & 424.15 & 423.45 & 420.6 & 420.75 & 420.3 & 420.3 \\
4 & X & 421.55 & 421.81 & 422.2 & 420.32 & 420.33 & 420.43 & 420.55 & 420.55 \\
& Y & 421.85 & 422.24 & 421.5 & 421.15 & 420.23 & 420.23 & 420.25 & 420.25 \\
5 & X & 424.32 & 424.69 & 423.91 & 423.35 & 420.48 & 420.7 & 420.6 & 420.6 \\
& Y & 423.82 & 424.15 & 423.44 & 422.92 & 420.86 & 421.1 & 421.12 & 421.12 \\
6 & X & 423,45 & 423.57 & 422.98 & 422.56 & 421 & 420.9 & 421.1 & 421.1 \\
& $\mathrm{Y}$ & 424.3 & 424.39 & 423.78 & 423.15 & 420.85 & 420.82 & 420.65 & 428.65 \\
\hline
\end{tabular}

Sumber. Manual Book MT. Ontari dan Laporan Overhaul

b. Piston ring macet dan patah.

Dari obserrvasi yang peneliti lakukan, macetnya piston ring menyebabkan pistonring tidak dapat bergerak bebas, karena tekanan dan suhu yang tinggi saat pembakaran, dan gerakan piston yang cepat saat mesin beroperasi, ring piston akan lebih cepat patah dan celah dari patah tersebut menyebabkan kotoran yang ikut terbakar serta minyak lumas yang ikut terbakar menyumbat lubang pelumasan silinder dan menjadi sebuah lumpur pembakaran yang menumpuk di scavenging air trunk.

c. Ruang udara bilas penuh lumpur pembakaran. 
Berdasarkan pengamatan peneliti selama penelitian di atas kapal MT. Ontari, tumpukan lumpur pembakaran dan minyak lumas ini dapat mengganggu suplai udara bilas dan tekanan scavenging air. Menyebabkan tekanan udara bilas turun dan berpengaruh terhadap komposisi pembakaran yang pembakaran tidak sempurna dan kualitas gas buang yang buruk.

d. Tekanan udara bilas di bawah normal.

Menurut hasil observasi peneliti dan data selama melakukan pelayaran, tekanan scavenging air tekanannya turun hanya 0,8 atm pada saaat Mesin Induk full away. Hal ini menyebabkan juga auxiliary blower harus bekerja berat karena yang seharusnya blower sudah tidak beroperasi masih harus beroperasi untuk membantu suplai udara bilas agar tekanannya normal.

e. Ketersediaan suku cadang Mesin Induk dan turbocharger di atas kapal. Dari hasil observasi yang peneliti lakukan, suku cadang Mesin Induk dan turbocharger untuk perawatan maupun perbaikan selalu diperhatikan oleh perusahaan. Setiap kali ada permintaan suku cadang yang dikirim dari kapal selalu mendapatkan respon yang baik dari perusahaan.

f. Pengecekan rutin pada kondisi piston, cylinder liner dan piston ring. Berdasarkan pengamatan peneliti, pengecekan rutin pada kondisi piston, cylinder liner dan piston ring dilakukan untuk mengetahui kondisi terkini dari kedua komponen mesin tersebut, sehingga jika terjadi kelainan maupun keadaan yang tidak normal dapat segera diatasi sebelum kerusakan semakin parah dan mempengaruhi komponen mesin lainnya. Pengecekan rutin ini dilakukan setiap 5000 jam kerja kecuali bila terjadi kelainan sebelum jam kerja tercapai maka akan diadakan pengecekan langsung tanpa memperhatikan jam kerja.

g. Pembersihan teratur pada ruang udara bilas.

Berdasarkan hasil observasi peneliti, pembersihan teratur pada ruang udara bilas dilakukan untuk menghindari adanya tumpukan kotoran sisa pembakaran maupun kotoran lain yang ikut terbakar yang tidak ikut terbuang melalu gas buang dan terkumpul di ruang udara bilas bersama sisa minyak lumas silinder.

h. Pengecekan dan perawatan rutin pada turbocharger. 
Menurut hasil observasi peneliti di atas kapal MT. Ontari, pengecekan, dan perawatan rutin pada turbocharger dilakukan pada penggantian filter turbocharger setiap seminggu sekali, penggantian minyak lumas setiap 3 bulan sekali, pengecekan level minyak lumas setiap turbocharger dalam keadaan beroperasi, pengetesan pada rotor turbin pada saat docking.

i. Kondisi laut yang mempengaruhi beban Mesin Induk.

Berdasarkan hasil pengamatan peneliti selama penelitian, kondisi laut laut yang ekstrim dengan gelombang tinggi dan arus dalam yang kuat menyebabkan Mesin Induk harus bekerja lebih berat. Sehingga, mempengaruhi komponen dari Mesin Induk dan turbocharger untuk menghasilkan daya dorong untuk kapal.

j. Suplai suku cadang Mesin Induk untuk di atas kapal terhambat.

Berdasarkan hasil observasi peneliti dan wawancara bahwa distribusi suku cadang untuk di atas kapal mengalami keterlambatan karena masalah perijininan dari maker ke perusahaan dan perusahaan ke pelabuhan atau kapal.

k. Kualitas suku cadang Mesin Induk yang tidak sesuai spesifikasi Mesin.

Berdasarkan hasil observasi peneliti, untuk menghemat biaya operasional kapal, perusahaan mengirimkan suku cadang ke kapal bukan asli dari maker, namun merupakan suku cadang aftermarket yang kualitasnya di bawah suku cadang original.

1. Waktu singgah kapal yang terlalu cepat.

Berdasarkan hasil observasi peneliti dan wawancara terhadap masinis II, waktu singgah kapal di pelabuhan maupun berlabuh terlalu singkat karena padatnya jadwal bongkar muat kapal dari charter, waktu yang singkat ini menurut pengamatan Peneliti menyulitkan engineer di atas kapal untuk melakukan perawatan dan perbaikan Mesin Induk dan turbocharger yang memang membutuhkan waktu dan tenaga yang lebih banyak dari permesinan lainnya serta bantuan dari kru mesin lainnya.

m. Annual survey dari perusahaan untuk mengecek langsung ke kapal.

Annual survey adalah langkah perusahaaan untuk datang langsung ke atas kapal melalui perwakilannya, dalam hal ini adalah superitendent yang bertujuan untuk mengetahui kondisi kapal secara langsung dan untuk pengecekan segala sesuatu yang ada di atas kapal. 
n. Perusahaan mempunyai agen distribusi untuk suku cadang.

Berdasarkan hasil observasi peneliti, perusahaan mempunyai kerja sama dengan agen distribusi suku cadang yang dapat memudahkan perusahaan dalam pemesanan dan pengiriman suku cadang ke kapal.

o. Peraturan docking wajib setiap 2 tahun dari perusahaan.

Berdasarkan hasil observasi peneliti di atas kapal MT. Ontari, perusahaan memiliki peraturan baik dari perusahaan pemilik kapal maupun charter bahwa kapal setiap 2 tahun sekali wajib melakukan docking untuk perawatan kapal.

p. Terdapat form diffect list untuk dilaporkan ke perusahaan.

Berdasarkan hasil observasi peneliti dan wawancara, diiffect list adalah sebuah daftar berisi permintaan suku cadang yang bersifat mendesak dan harus segera di respon oleh perusahaaan demi kelancaran operasional kapal.

2. Upaya apa yang dilakukan untuk mengatasi faktor-faktor penyebab surging Mesin Diesel Penggerak Utama:

Dari faktor-faktor penyebab di atas tersebut dikelompokan masing-masing berdasarakan metode pengambilan keputusan yaitu SWOT (Strength, Weakness, Opportunities, Threats). Dari faktor tersebut Peneliti mengambil penyelesaian terhadap faktor kelemahan (weakness) dan ancaman (threats) yang terjadi ketika Peneliti penelitian sedangkan faktor kekuatan (strength) dan peluang (opportunities) tidak ada penyelesainnya karena merupakan hal yang positif dan perlu dipertahankan. Adapun faktor-faktor kelemahan dan ancaman tersebut adalah sebagai berikut:

a. Lolosnya kompresi pada saat pembakaran.

Berdasarkan hasil observasi peneliti dan wawancara dengan masinis II sebagai penanggung jawab dari Mesin Induk mengatakan "adapun upaya yang dilakukan untuk mengatasi masalah tersebut dengan mengganti cylinder liner yang sudah oversize tersebut dengan suku cadang yang baru karena diameter cylinder liner 5 dari 6 silinder yang ada melebihi batas toleransi maksimal".

Namun yang terjadi di atas kapal MT. Ontari adalah tidak bisa dilakukan penggantian cylinder liner karena tidak adanya suku cadang, sehingga 
ditempuh cara alternatif untuk mengurangi dampak dari oversize cylinder liner tersebut terutama terhadap surging dengan cara:

1). Menurunkan putaran Mesin Induk agar pembakaran lebih stabil dan gas buang yang dihasilkan lebih stabil.

2). Mengurangi konsumsi minyak lumas silinder, sehingga tidak banyak minyak lumas silinder yang lolos dan terbakar menjadi lumpur di ruang udara bilas.

3). Mengoperasikan auxiliary blower secara manual untuk mensuplai udara bilas agar sesuai tekanan dengan Mesin Induk.

b. Piston ring macet dan patah

Dari hasil observasi serta studi pustaka yang dilakukan peneliti, terdapat beberapa cara agar piston ring tidak macet dan patah adalah sebagai berikut:

1. Pembersihan piston groove dan piston crown dari kerak pembakaran dan kotoran yang menempel menggunakan brush pada saat top overhaul.

2. Penggantian piston ring yang sudah patah dengan piston ring yang baru agar kinerja piston ring tetap baik dan optimal sesuai dengan fungsinya

3. Pengecekan rutin piston ring secara rutin seminggu sekali untuk mencegah piston ring patah. Apalagi setelah terjadi surging maka segera dilakukan pengecekan piston ring karena hasil observasi dari Peneliti dan masinis II setelah surging dan dilakukan pengecekan piston ring, terdapat piston ring yang patah terutama pada cylinder liner yang mengalami oversize.

c. Ruang udara bilas penuh lumpur pembakaran

Dari hasil observasi dan wawancara dengan Masinis II mengatakan "cara mengatasi ruang udara bilas yang penuh lumpur pembakaran dan mengganggu suplai udara bilas adalah sebagai berikut:

1. Pembersihan secara rutin ruang udara bilas dari lumpur pembakaran setiap seminggu sekali setelah melakukan pelayaran. Kegiatan ini juga sekaligus digunakan untuk melakukan pengecekan patah atau tidaknya piston ring.

2. Mengurangi jumlah volume minyak lumas silinder antara manuver dengan full away. Hal ini dimaksudkan agar tidak terlalu banyak 
minyak lumas silinder yang ikut terbakar dan jatuh ke ruang udara bilas yang merupakan dampak dari groove piston yang tersumbat sehingga pelumasan tidak dapat melalui groove tersebut untuk melumasi piston ring dan cylinder liner dan sisa minyak lumas silinder yang ikut terbakar akan terkumpul di ruang udara bilas.

d. Tekanan udara bilas di bawah normal.

Berdasarkan hasil observasi peneliti dan melalui studi pustaka dari buku manual mesin induk, tekanan udara bilas turun dapat diketahui dari hasil analisa Main Engine Performance yang menurun dan terjadinya kenaikan temperatur gas buang yang rata-rata setiap silinder mencapai batas toleransi $385^{\circ} \mathrm{C}$, dan tekanan scaving air menjadi rendah, hanya 0,8 bar saat mesin berputar konstan $120 \mathrm{Rpm}$. Dan pengamatan langsung terhadap manhole scavenging air yang di dalamnya terdapat banyak lumpur kotoran bekas pembakaran yang bercampur oli. Agar tidak terjadi dampak yang lebih luas, dilakukan cara:

1. Putaran Mesin Induk diturunkan di bawah batas normal (MCR).

2. Dilakukan pengecekan rutin pada motor auxiliary blower terutama suhu, karena harus bekerja terus menerus sehingga dikawatirkan motor akan panas dan terbakar.

\section{Pembahasan Masalah}

1. Faktor Kunci Keberhasilan (FKK) untuk mencari kuadran strategi SWOT

a. Faktor Internal dan Eksternal

Setelah didapatkan faktor-faktor yang mendukung maupun yang menyebabkan surging, maka kemudian dikelompokkan dalam tabel faktor internal dan eksternal untuk memudahkan pengidentifikasian, sebagaimana terlihat pada Tabel 2 berikut ini:

\section{Tabel 2. Faktor Internal dan Faktor Eksternal}

\begin{tabular}{|c|c|c|c|}
\hline \multicolumn{4}{|c|}{ Faktor Internal } \\
\hline No & Kekuatan (S) & No & Kelemahan $(W)$ \\
\hline 1 & $\begin{array}{l}\text { Ketersediaan suku cadang Mesin } \\
\text { Induk dan turbocharger di atas } \\
\text { kapal }\end{array}$ & 1 & $\begin{array}{l}\text { Tekanan udara bilas di bawah } \\
\text { normal }\end{array}$ \\
\hline 2 & $\begin{array}{l}\text { Pengecekan rutin pada kondisi } \\
\text { piston, cylinder liner dan piston } \\
\text { ring }\end{array}$ & 2 & Piston ring macet dan patah \\
\hline 3 & $\begin{array}{l}\text { Pembersihan teratur pada ruang } \\
\text { udara bilas }\end{array}$ & 3 & $\begin{array}{l}\text { Ruang udara bilas penuh lumpur } \\
\text { pembakaran }\end{array}$ \\
\hline 4 & Pengecekan dan perawatan rutin & 4 & Lolosnya kompresi \\
\hline
\end{tabular}




\begin{tabular}{c|lcl}
\hline \multicolumn{1}{c}{} & pada turbocharger & \multicolumn{2}{c}{ pembakaran } \\
\hline \multicolumn{1}{c}{ Peluang (O) } & Faktor Eksternal \\
\hline No & \multicolumn{1}{|c}{ No } & \multicolumn{1}{c}{ Ancaman (T) } \\
\hline 1 & $\begin{array}{l}\text { Annual Survey dari perusahaan } \\
\text { untuk mengecek langsung ke kapal }\end{array}$ & 1 & $\begin{array}{l}\text { Suplai suku cadang Mesin Induk } \\
\text { untuk di atas kapal terhambat }\end{array}$ \\
2 & $\begin{array}{l}\text { Perusahaan mempunyai agen } \\
\text { distribusi untuk suku cadang }\end{array}$ & 2 & $\begin{array}{l}\text { Kondisi laut yang mempengaruhi } \\
\text { beban Mesin Induk }\end{array}$ \\
3 & $\begin{array}{l}\text { Peraturan docking wajib setiap 2 } \\
\text { tahun dari perusahaan }\end{array}$ & 3 & $\begin{array}{l}\text { Kualitas suku cadang Meisn Induk } \\
\text { yang tidak sesuai spesifikasi Mesin }\end{array}$ \\
4 & $\begin{array}{l}\text { Terdapat form diffect list untuk } \\
\text { dilaporkan ke perusahaan }\end{array}$ & 4 & $\begin{array}{l}\text { Waktu singgah kapal yang terlalu } \\
\text { cepat }\end{array}$ \\
\hline
\end{tabular}

b. Komparasi Urgensi Faktor Internal dan Eksternal.

Digunakan untuk menentukan Bobot Faktor (BF), dapat dilihat pada tabel 3 di bawah ini:

\section{Tabel 3. Komparasi Urgensi Faktor Internal dan Eksternal}

\begin{tabular}{|c|c|c|c|c|c|c|c|c|c|c|c|}
\hline No & Faktor Internal & $A$ & $\boldsymbol{B}$ & $C$ & $D$ & $E$ & $F$ & $G$ & $\boldsymbol{H}$ & $\begin{array}{l}N \\
U\end{array}$ & $\begin{array}{l}B F \\
(\%)\end{array}$ \\
\hline $\mathrm{A}$ & $\begin{array}{l}\text { Ketersediaan suku cadang } \\
\text { Mesin Induk dan } \\
\text { turbocharger di atas kapal }\end{array}$ & & $\mathrm{A}$ & $\mathrm{C}$ & $\mathrm{A}$ & $E$ & $\mathrm{~F}$ & A & $\mathrm{H}$ & 3 & 10.71 \\
\hline $\mathrm{B}$ & $\begin{array}{l}\text { Pengecekan rutin pada } \\
\text { kondisi piston, cylinder } \\
\text { liner dan piston ring }\end{array}$ & A & & $\mathrm{C}$ & $\mathrm{D}$ & $\mathrm{E}$ & $\mathrm{F}$ & B & $\mathrm{H}$ & 1 & 3.57 \\
\hline $\mathrm{C}$ & $\begin{array}{l}\text { Pembersihan teratur pada } \\
\text { ruang udara bilas }\end{array}$ & $\mathrm{C}$ & $\mathrm{C}$ & & $\mathrm{C}$ & $\mathrm{E}$ & $\mathrm{F}$ & G & $\mathrm{H}$ & 3 & 10.71 \\
\hline $\mathrm{D}$ & $\begin{array}{l}\text { Pengecekan } \\
\text { perawatan rutin pada } \\
\text { turbocharger }\end{array}$ & A & $\mathrm{D}$ & $\mathrm{C}$ & 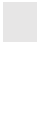 & $\mathrm{E}$ & $\mathrm{F}$ & $\mathrm{D}$ & $\mathrm{H}$ & 2 & 7.14 \\
\hline $\mathrm{E}$ & $\begin{array}{l}\text { Tekanan udara bilas di } \\
\text { bawah normal }\end{array}$ & $\mathrm{E}$ & $\mathrm{E}$ & $\mathrm{E}$ & $\mathrm{E}$ & . & $\mathrm{E}$ & G & $\mathrm{H}$ & 5 & 17.86 \\
\hline $\mathrm{F}$ & $\begin{array}{l}\text { Piston ring macet dan } \\
\text { patah }\end{array}$ & $\mathrm{F}$ & $\mathrm{F}$ & $\mathrm{F}$ & $\mathrm{F}$ & $\mathrm{E}$ & . & $\mathrm{F}$ & $\mathrm{H}$ & 5 & 17.86 \\
\hline $\mathrm{G}$ & $\begin{array}{l}\text { Ruang udara bials penuh } \\
\text { lumpur pembakaran }\end{array}$ & A & B & $\mathrm{G}$ & $\mathrm{D}$ & $\mathrm{G}$ & $\mathrm{F}$ & & G & 3 & 10.71 \\
\hline $\mathrm{H}$ & $\begin{array}{l}\text { Lolosnya kompresi pada } \\
\text { saat pembakaran }\end{array}$ & $\mathrm{H}$ & $\mathrm{H}$ & $\mathrm{H}$ & $\mathrm{H}$ & $\mathrm{H}$ & $\mathrm{H}$ & G & 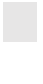 & 6 & 21.43 \\
\hline & Jumlah & 3 & 1 & 3 & 2 & 5 & 5 & 3 & 6 & $\begin{array}{l}2 \\
8\end{array}$ & 100.0 \\
\hline No & Faktor Eksternal & $A$ & $\boldsymbol{B}$ & $C$ & $D$ & $E$ & $F$ & $G$ & $\boldsymbol{H}$ & $\begin{array}{l}\boldsymbol{N} \\
\boldsymbol{U} \\
\end{array}$ & $\begin{array}{l}B F \\
(\%)\end{array}$ \\
\hline $\mathrm{A}$ & 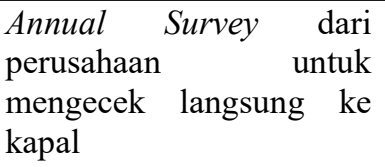 & & $\mathrm{A}$ & $A$ & $\mathrm{~A}$ & $E$ & $\mathrm{~F}$ & $\mathrm{G}$ & $\mathrm{H}$ & 3 & 10.71 \\
\hline B & $\begin{array}{l}\text { Perusahaan mempunyai } \\
\text { agen distribusi untuk } \\
\text { suku cadang }\end{array}$ & A & & B & D & $\mathrm{E}$ & $\mathrm{F}$ & $\mathrm{G}$ & $\mathrm{H}$ & 1 & 3.57 \\
\hline $\mathrm{C}$ & $\begin{array}{lrr}\text { Peraturan docking } & \text { wajib } \\
\text { setiap } 2 & \text { tahun } \\
\text { perusahaan } & & \end{array}$ & A & B & & $\mathrm{D}$ & $\mathrm{E}$ & $\mathrm{F}$ & $\mathrm{G}$ & $\mathrm{H}$ & 0 & - \\
\hline $\mathrm{D}$ & $\begin{array}{l}\text { Terdapat form diffect list } \\
\text { untuk dilaporkan ke } \\
\text { perusahaan }\end{array}$ & A & $\mathrm{D}$ & $\mathrm{D}$ & & $\mathrm{E}$ & $\mathrm{D}$ & $\mathrm{G}$ & $\mathrm{H}$ & 3 & 10.71 \\
\hline
\end{tabular}




\begin{tabular}{|c|c|c|c|c|c|c|c|c|c|c|c|}
\hline E & $\begin{array}{l}\text { Suplai suku cadang } \\
\text { Mesin Induk untuk di atas } \\
\text { kapal terhambat }\end{array}$ & E & E & E & E & & E & E & E & 7 & 25.00 \\
\hline F & $\begin{array}{l}\text { Kondisi laut yang } \\
\text { mempengaruhi } \\
\text { Mesin Induk }\end{array}$ & $\mathrm{F}$ & $\mathrm{F}$ & $\mathrm{F}$ & D & E & 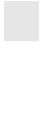 & $\mathrm{F}$ & $\mathrm{F}$ & 5 & 17.86 \\
\hline G & $\begin{array}{l}\text { Kualitas suku cadang } \\
\text { Meisn Induk yang tidak } \\
\text { sesuai spesifikasi Mesin }\end{array}$ & $\mathrm{G}$ & G & G & G & E & $\mathrm{F}$ & 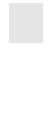 & G & 5 & 17.86 \\
\hline \multirow[t]{2}{*}{$\mathrm{H}$} & $\begin{array}{l}\text { Waktu singgah kapal } \\
\text { yang terlalu cepat }\end{array}$ & $\mathrm{H}$ & $\mathrm{H}$ & $\mathrm{H}$ & $\mathrm{H}$ & E & $\mathrm{F}$ & G & $\square$ & 4 & 14.29 \\
\hline & Jumlah & 3 & 1 & 0 & 3 & 7 & 5 & 5 & 4 & $\begin{array}{l}2 \\
8\end{array}$ & 100.0 \\
\hline
\end{tabular}

\section{c. Dukungan Faktor.}

Setelah bobot faktor diketahui, berikutnya dilakukan penentuan Nilai Dukungan (ND). Penilaian tersebut peneliti dapatkan dari kuisioner kepada Pasis ATT II yang dikapalnya terdapat turbocharger (rekapitulasi hasil diskusi dapat dilihat pada lampiran 7). Adapun Nilai Dukung adalah sebagai berikut:

\begin{tabular}{|c|c|c|}
\hline & Faktor Internal & $\overline{N D}$ \\
\hline 1 & $\begin{array}{l}\text { Ketersediaan suku cadang Mesin Induk dan turbocharger di } \\
\text { atas kapal }\end{array}$ & 3 \\
\hline 2 & $\begin{array}{l}\text { Pengecekan rutin pada kondisi piston, cylinder liner dan piston } \\
\text { ring }\end{array}$ & 3 \\
\hline 3 & Pembersihan teratur pada ruang udara bilas & 4 \\
\hline 4 & Pengecekan dan perawatan rutin pada turbocharger & 3 \\
\hline 5 & Tekanan udara bilas di bawah normal & 4 \\
\hline 6 & Piston ring macet dan patah & 4 \\
\hline 7 & Ruang udara bials penuh lumpur pembakaran & 4 \\
\hline \multirow[t]{2}{*}{8} & Lolosnya kompresi pada saat pembakaran & 4 \\
\hline & Faktor Eksternal & $N D$ \\
\hline 1 & $\begin{array}{l}\text { Annual Survey dari perusahaan untuk mengecek langsung ke } \\
\text { kapal }\end{array}$ & 2 \\
\hline 2 & Perusahaan mempunyai agen distribusi untuk suku cadang & 2 \\
\hline 3 & Peraturan docking wajib setiap 2 tahun dari perusahaan & 1 \\
\hline 4 & Terdapat form diffect list untuk dilaporkan ke perusahaan & 3 \\
\hline 5 & Suplai suku cadang Mesin Induk untuk di atas kapal terhambat & 4 \\
\hline 6 & Kondisi laut yang mempengaruhi beban Mesin Induk & 3 \\
\hline 7 & $\begin{array}{l}\text { Kualitas suku cadang Meisn Induk yang tidak sesuai } \\
\text { spesifikasi Mesin }\end{array}$ & 3 \\
\hline 8 & Waktu singgah kapal yang terlalu cepat & 3 \\
\hline
\end{tabular}

\section{d. Nilai Relatif Keterkaitan Faktor-Faktor.}

Dengan adanya keterkaitan itulah, maka akan tercipta suatu sinergi dalam mendukung permasalahan. Untuk itu perlu ditentukan Nilai Relatif Keterkaitan (NRK) tiap faktor dengan faktor lainnya. 
Tazani, A. A, Santiko, T, Tjahjono, A. A, Sapan, Y.

Tabel 5. Nilai Relatif Keterkaitan (NRK) Faktor Internal dan Eksternal

\begin{tabular}{|c|c|c|c|c|c|c|c|c|c|c|c|c|c|c|c|c|c|c|}
\hline & $\begin{array}{c}\text { Faktor Internal dan } \\
\text { Eksternal }\end{array}$ & 1 & 2 & 3 & 4 & 5 & $\overline{6}$ & 7 & 8 & 9 & 10 & 11 & 12 & 13 & 14 & 15 & 16 & $\begin{array}{c}N R \\
K\end{array}$ \\
\hline No & Faktor Internal & & & & & & & & & & & & & & & & & \\
\hline 1 & $\begin{array}{l}\text { Ketersediaan suku } \\
\text { cadang Mesin Induk } \\
\text { dan turbocharger di } \\
\text { atas kapal }\end{array}$ & 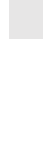 & 3 & 3 & 3 & 3 & 3 & 3 & 3 & 3 & 3 & 1 & 2 & 3 & 1 & 2 & 2 & $\begin{array}{c}2.5 \\
3\end{array}$ \\
\hline 2 & $\begin{array}{l}\text { Pengecekan rutin } \\
\text { pada kondisi piston, } \\
\text { cylinder liner dan } \\
\text { piston ring }\end{array}$ & 3 & 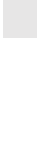 & 2 & 3 & 2 & 3 & 2 & 3 & 3 & 2 & 2 & 1 & 1 & 2 & 1 & 1 & $\begin{array}{c}2.0 \\
7\end{array}$ \\
\hline 3 & $\begin{array}{l}\text { Pembersihan teratur } \\
\text { pada ruang udara } \\
\text { bilas }\end{array}$ & 3 & 2 & 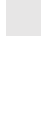 & 4 & 4 & 3 & 3 & 3 & 3 & 3 & 2 & 2 & 3 & 2 & 3 & 1 & $\begin{array}{c}2.7 \\
3\end{array}$ \\
\hline 4 & $\begin{array}{l}\text { Pengecekan dan } \\
\text { perawatan rutin pada } \\
\text { turbocharger }\end{array}$ & 3 & 3 & 4 & 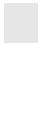 & 3 & 3 & 2 & 3 & 3 & 1 & 2 & 2 & 4 & 3 & 2 & 2 & $\begin{array}{c}2.6 \\
7\end{array}$ \\
\hline 5 & $\begin{array}{l}\text { Tekanan udara bilas } \\
\text { di bawah normal }\end{array}$ & 3 & 2 & 4 & 3 & 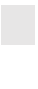 & 4 & 2 & 2 & 3 & 2 & 3 & 1 & 3 & 3 & 1 & 1 & $\begin{array}{c}2.4 \\
7\end{array}$ \\
\hline 6 & $\begin{array}{l}\text { Piston ring macet } \\
\text { dan patah }\end{array}$ & 3 & 3 & 3 & 3 & 4 & 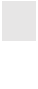 & 4 & 4 & 2 & 1 & 1 & 1 & 2 & 3 & 4 & 2 & $\begin{array}{c}2.6 \\
7\end{array}$ \\
\hline 7 & $\begin{array}{l}\text { Ruang udara bials } \\
\text { penuh lumpur } \\
\text { pembakaran }\end{array}$ & 3 & 2 & 3 & 2 & 2 & 4 & 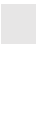 & 4 & 1 & 1 & 3 & 1 & 3 & 3 & 3 & 2 & $\begin{array}{c}2.4 \\
7\end{array}$ \\
\hline 8 & $\begin{array}{lr}\text { Lolosnya } & \text { kompresi } \\
\text { pada } & \text { saat } \\
\text { pembakaran } & \end{array}$ & 3 & 3 & 3 & 3 & 2 & 4 & 4 & 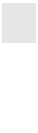 & 4 & 3 & 1 & 1 & 4 & 4 & 4 & 2 & $\begin{array}{c}3.0 \\
0\end{array}$ \\
\hline No & Faktor Eksternal & 1 & 2 & 3 & 4 & 5 & 6 & 7 & 8 & 9 & 10 & 11 & 12 & 13 & 14 & 15 & 16 & $\begin{array}{c}N R \\
K \\
\end{array}$ \\
\hline 9 & $\begin{array}{l}\text { Annual Survey dari } \\
\text { perusahaan untuk } \\
\text { mengecek langsung } \\
\text { ke kapal }\end{array}$ & 3 & 3 & 3 & 3 & 3 & 2 & 1 & 4 & & 2 & 3 & 3 & 3 & 2 & 2 & 1 & $\begin{array}{c}2.5 \\
3\end{array}$ \\
\hline 10 & $\begin{array}{l}\text { Perusahaan } \\
\text { mempunyai agen } \\
\text { distribusi untuk suku } \\
\text { cadang }\end{array}$ & 3 & 2 & 3 & 1 & 2 & 1 & 1 & 3 & 2 & 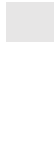 & 3 & 2 & 3 & 2 & 2 & 1 & $\begin{array}{c}2.0 \\
7\end{array}$ \\
\hline 11 & $\begin{array}{l}\text { Peraturan docking } \\
\text { wajib setiap } 2 \text { tahun } \\
\text { dari perusahaan }\end{array}$ & 1 & 2 & 2 & 2 & 3 & 1 & 3 & 1 & 3 & 3 & - & 2 & 2 & 3 & 2 & 1 & $\begin{array}{c}2.0 \\
7\end{array}$ \\
\hline 12 & $\begin{array}{lr}\text { Terdapat } & \text { form } \\
\text { diffect list } & \text { untuk } \\
\text { dilaporkan } & \text { ke } \\
\text { perusahaan } & \end{array}$ & 2 & 1 & 2 & 2 & 1 & 1 & 1 & 1 & 3 & 2 & 2 & 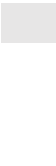 & 2 & 3 & 2 & 2 & $\begin{array}{c}1.8 \\
0\end{array}$ \\
\hline 13 & $\begin{array}{ll}\text { Suplai suku cadang } \\
\text { Mesin Induk untuk } \\
\text { di atas kapal } \\
\text { terhambat }\end{array}$ & 3 & 1 & 3 & 4 & 3 & 2 & 3 & 4 & 3 & 3 & 2 & 2 & . & 4 & 3 & 3 & $\begin{array}{c}2.8 \\
7\end{array}$ \\
\hline 14 & $\begin{array}{l}\text { Kondisi laut yang } \\
\text { mempengaruhi } \\
\text { beban Mesin Induk }\end{array}$ & 1 & 2 & 2 & 3 & 3 & 3 & 3 & 4 & 2 & 2 & 3 & 3 & 4 & & 2 & 1 & $\begin{array}{c}2.5 \\
3\end{array}$ \\
\hline 15 & $\begin{array}{l}\text { Kualitas suku } \\
\text { cadang Meisn Induk } \\
\text { yang tidak sesuai } \\
\text { spesifikasi Mesin }\end{array}$ & 2 & 1 & 3 & 2 & 1 & 4 & 3 & 4 & 2 & 2 & 2 & 2 & 3 & 2 & & 4 & $\begin{array}{c}2.5 \\
7\end{array}$ \\
\hline 16 & Waktu singgah & 2 & 1 & 1 & 2 & 1 & 2 & 2 & 2 & 1 & 1 & 1 & 2 & 3 & 1 & 4 & & 1.7 \\
\hline
\end{tabular}




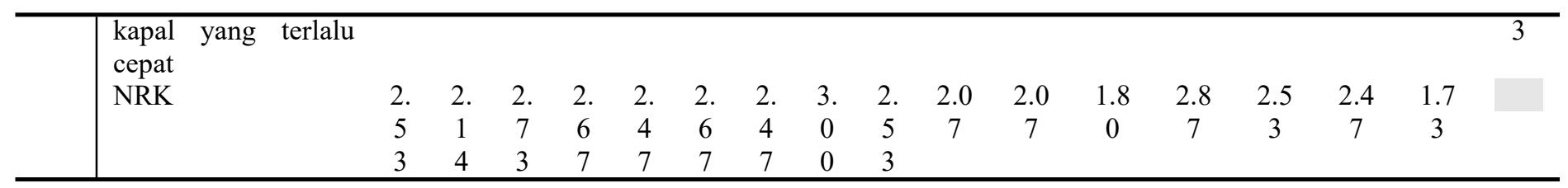

e. Matriks Ringkasan Analisis Faktor Internal dan Eksternal.

Setelah mendapatkan bobot faktor (BF), nilai dukung (ND) serta nilai relatif

keterkaitan (NRK), kemudian langkah selanjutnya adalah Peneliti menentukan

Total Nilai Bobot (TNB).

Tabel 6. Matriks Ringkasan Analisis Faktor Internal dan Eksternal

\begin{tabular}{|c|c|c|c|c|c|c|c|c|c|c|}
\hline No & $\begin{array}{c}\text { Faktor } \\
\text { Internal }\end{array}$ & $\begin{array}{l}\text { BF } \\
\% \\
\end{array}$ & ND & NBD & NRK & NBK & TNB & FKK & JML & TNB \\
\hline 1 & $\begin{array}{l}\text { Ketersediaan } \\
\text { suku cadang } \\
\text { Mesin Induk } \\
\text { dan } \\
\text { turbocharger } \\
\text { di atas kapal }\end{array}$ & 10.71 & 3 & 0.32 & 2.53 & 0.27 & 0.59 & & $\mathrm{~S}$ & 1.90 \\
\hline 2 & $\begin{array}{l}\text { Pengecekan } \\
\text { rutin pada } \\
\text { kondisi } \\
\text { piston, } \\
\text { cylinder liner } \\
\text { dan piston } \\
\text { ring }\end{array}$ & 3.57 & 3 & 0.11 & 2.07 & 0.07 & 0.18 & & & \\
\hline 3 & $\begin{array}{l}\text { Pembersihan } \\
\text { teratur pada } \\
\text { ruang udara } \\
\text { bilas }\end{array}$ & 10.71 & 4 & 0.43 & 2.73 & 0.29 & 0.72 & & & \\
\hline 4 & $\begin{array}{l}\text { Pengecekan } \\
\text { dan } \\
\text { perawatan } \\
\text { rutin pada } \\
\text { turbocharger }\end{array}$ & 7.14 & 3 & 0.21 & 2.67 & 0.19 & 0.40 & & & \\
\hline 5 & $\begin{array}{l}\text { Tekanan } \\
\text { udara bilas di } \\
\text { bawah normal }\end{array}$ & 17.86 & 4 & 0.71 & 2.47 & 0.44 & 1.16 & & W & 4.54 \\
\hline 6 & $\begin{array}{lr}\text { Piston ring } \\
\text { macet } \\
\text { patah }\end{array}$ & 17.86 & 4 & 0.71 & 2.67 & 0.48 & 1.19 & & & \\
\hline 7 & $\begin{array}{l}\text { Ruang udara } \\
\text { bials penuh } \\
\text { lumpur } \\
\text { pembakaran }\end{array}$ & 10.71 & 4 & 0.43 & 2.47 & 0.26 & 0.69 & & & \\
\hline \multirow[t]{2}{*}{8} & $\begin{array}{l}\text { Lolosnya } \\
\text { kompresi } \\
\text { pada saat } \\
\text { pembakaran }\end{array}$ & 21.43 & 4 & 0.86 & 3 & 0.64 & 1.50 & I & & \\
\hline & $\begin{array}{c}\text { Faktor } \\
\text { Eksternal }\end{array}$ & & & & & & & & & \\
\hline 9 & $\begin{array}{l}\text { Annual } \\
\text { Survey dari } \\
\text { perusahaan }\end{array}$ & 10.71 & 2 & 0.21 & 2.53 & 0.27 & 0.49 & & $\mathrm{O}$ & 1.14 \\
\hline
\end{tabular}




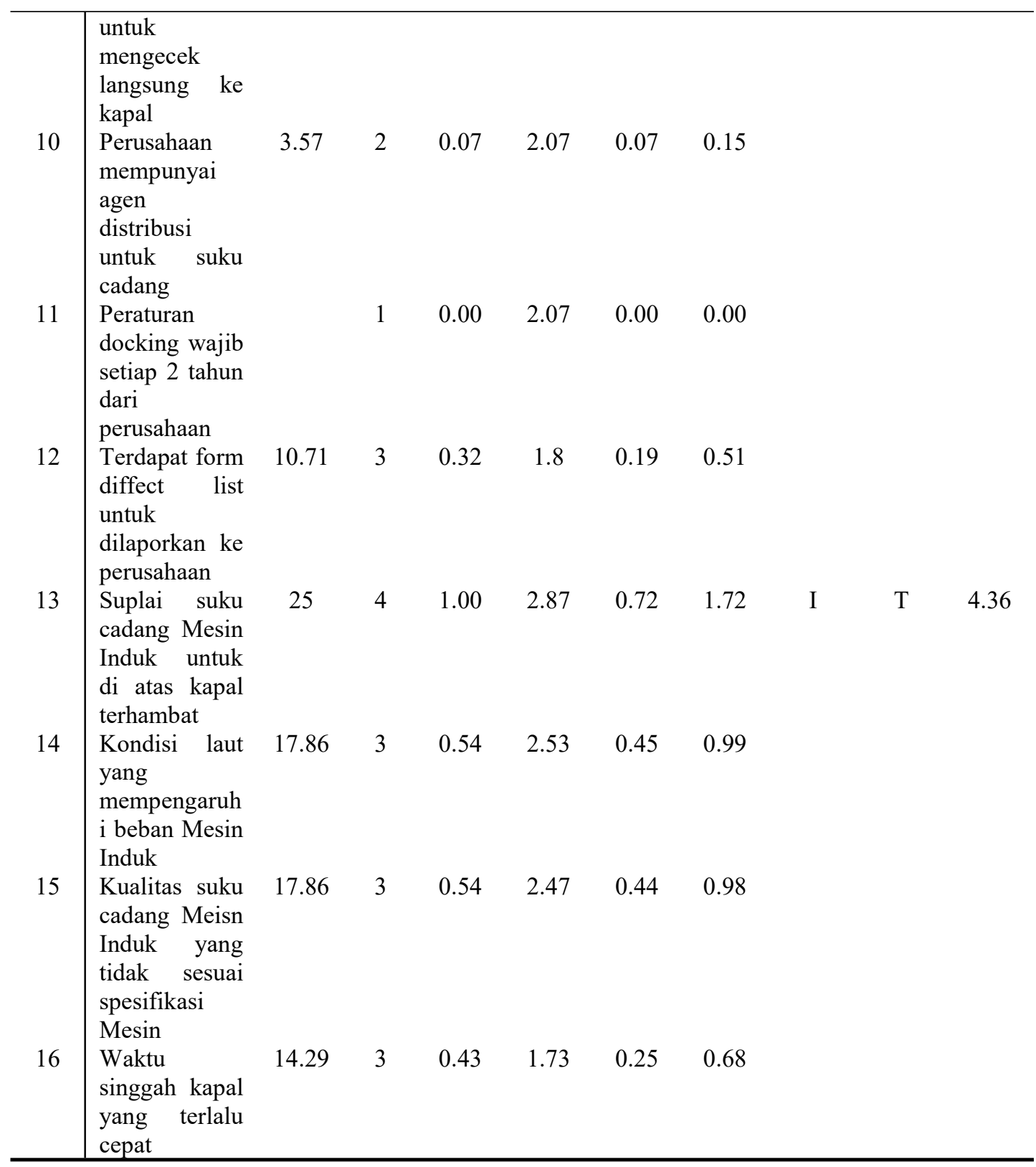

\section{f. Peta Kuadran Strategi.}

Dari hasil penilaian terhadap faktor-faktor yang telah disusun di dalam matrik ringkasan analisis faktor internal dan eksternal di atas dapat digunakan untuk menentukan peta kuadran strategi. Dimana nilai jumlah TNB kekuatan $(\mathrm{S})=1,90$ dan nilai jumlah TNB kelemahan $(\mathrm{W})=4,54$ maka selisihnya $(\mathrm{Y})=\mathrm{S}-\mathrm{W}$ maka hasilya $\mathrm{Y}=-2,64$, sedangkan nilai jumlah TNB peluang $(\mathrm{O})=1,14$ dan nilai jumlah TNB ancaman $(\mathrm{T})=4,36$ maka hasil selisihnya $(\mathrm{X})=\mathrm{O}-\mathrm{T}$ dan hasilnya 3,22 maka titik tersebut berada di (-3,22:-2.64) atau dapat diketahui bahwa peta kuadran strategi berada di kuadran IV (Strategi Defensive), maka strategi yang dilakukan yaitu mengurangi kelemahan untuk mengatasi ancaman dengan 
langkah- langkah yang dijelaskan pada bagian upaya yang dilakukan untuk mengatasi faktor-faktor penyebab turbocharger. Adapun peta kuadran strategi tersebut adalah sebagai berikut:

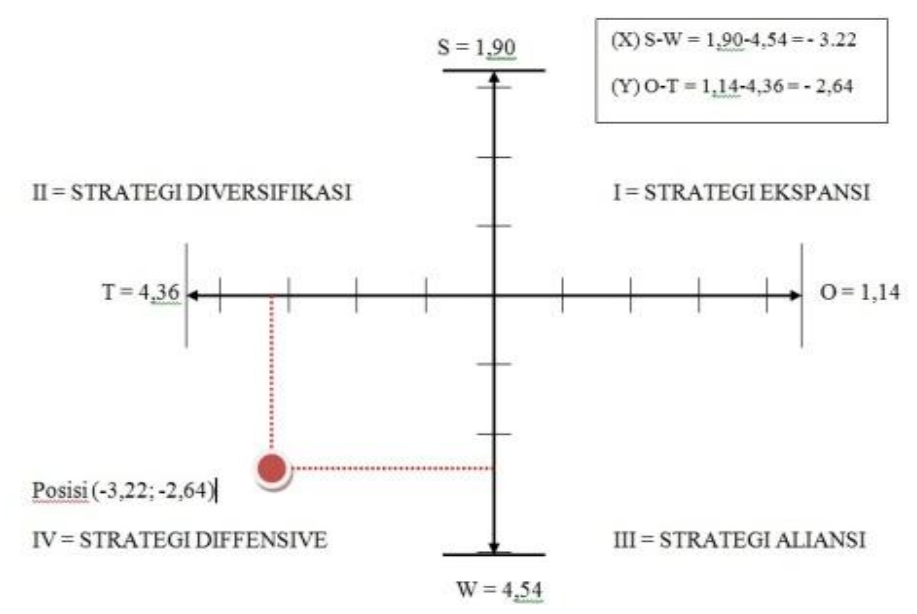

Gambar 2. Kuadran Strategi SWOT

Berdasarkan hasil pengolahan faktor-faktor ekternal dan internal menggunakan analisis SWOT yang didukung dengan hasil studi pustaka serta hasil wawancara yang Peneliti lakukan pada saat melaksanakan penelitian di MT. Ontari dan hasil kuisioner yang diberikan kepada Pasis ATT II di PIP Semarang, maka diperoleh faktor kunci keberhasilan dari faktor kelemahan dan ancaman yang menyebabkan surging Mesin Induk, yaitu

a. Lolosnya kompresi pada saat pembakaran

b. Suplai suku cadang Mesin Induk untuk di atas kapal terhambat.

2. Pembahasan kesimpulan penelitian hasil kuadran SWOT

Dari pembahasan masalah di atas, dapat disimpulkan bahwa ada 2 faktor yang telah diprioritaskan pada pembahasan faktor kunci keberhasilan. Adapun pembahasan dari kedua faktor tersebut adalah sebagai berikut:

a. Lolosnya kompresi pada saat pembakaran

Dari observasi peneliti saat melakukan penelitian di atas kapal MT. Ontari, pembakaran yang tidak sempurna dan tekanan udara bilas yang turun di bawah normal disebabkan karena pada kondisi di kapal MT. Ontari, oversize cylinder liner yang sudah melebihi batas toleransi maksimal. 
Pembakaran dan kompresi yang lolos menyebabkan miyak pelumas cylinder liner ikut terbakar bersama kotoran yang ikut terbawa bersama bahan bakar dan udara penjalan di ruang silinder dan menghasilkan kerak karbon sisa pembakaran yang melekat pada dinding silinder maupun di kepala piston serta menyebabkan lumpur pembakaran yang bercampur dengan sisa minyak lumas silinder pada stuffing box.

Sedangkan, lumpur pembakaran yang berada di scavenging air dapat mengganggu suplai tekanan udara bilas dan mengakibatkan tekanan udara bilas yang berada di bawah normal yang diakibatkan dari banyaknya tumpukan lumpur sisa pembakaran di dalam ruang udara bilas, sehingga suplai udara bilas menjadi terganggu dengan adanya tumpukan lumpur sisa pembakaran tersebut.

Kualitas gas buang yang buruk akan berpengaruh kepada putaran turbocharger yang naik turun. Berdasarkan hasil observasi, wawancara dengan masinis II, studi pustaka dari manual book troubleshooting Main Engine MT. Ontari bahwa kenaikan suhu gas buang akibat dari pembakaran yang tidak sempurna, gas buang Mesin Induk MT. Ontari mencapai batas tolerani $385^{\circ} \mathrm{C}$ dengan tekanan scavenging air sebesar 0.8 bar menyebabkan kualitas gas buang yang sangat buruk untuk memutar turbin side pada turbocharger. Apabila gas buang yang dihasilkan tidak sesuai dengan spesifikasi yang dibutuhkan turbocharger, maka putaran turbocharger pun tidak optimal.

Hal ini mengakibatkan surging yang terjadi karena kejadian turbocharger mengalami overrunning lalu berhenti seketika, kemudian berputar dengan normal kembali, tidak berapa lama overrunning kembali. Saat akan terjadi surging, kompresor akan berputar dengan putaran di atas putaran normalnya (overrunning), hal ini terjadi karena kompresor tidak menghasilkan udara bertekanan yang di suplai ke dalam Main Engine, sehingga seolah-olah turbocharger berputar tanpa beban. Surging terjadi karena getaran frekuansi tinggi dari impeller (rotor) yang berputar pada keadaan tertentu dan kompresor udara harus menyalurkan udara dengan tekanan tertentu sesuai dengan putaran turbine dan karena suatu sebab tekanan udara di dalam ruang pembilasan (scaving air trunk) sama atau lebih tinggi dibandingkan dengan tekanan udara yang dihasilkan oleh blower kompresor maka ada kecenderungan tekanan udara membalik arah melawan sudu blower yang berputar. 
b. Suplai suku cadang Mesin Induk untuk di atas kapal terhambat Keadaan ini menyulitkan bagi engineer di atas kapak untuk melakukan perawatan dan perbaikan terhadap Mesin Induk yaitu oversize cylinder liner yang sudah melebihi batas toleransi maksimal dan harus segera dilakukan penggantian dengan yang baru. Namun permintaan cylinder liner dari kapal ke perusahaan hingga peneliti selesai melakukan penelitian pada tanggal 4 Januari 2017, suku cadang cylinder liner belum juga dikirim ke atas kapal sehingga belum dilakukan peggantian cylinder liner dengan yang baru.

3. Upaya mengatasi faktor utama hasil kuadran strategi SWOT

Dari hasil penilaian dalam Matrik Ringkasan Analisa faktor internal dan eksternal yang kemudian dijabarkan pada peta kuadran strategi dapat diketahui bahwa peta kuadran strategi berada di kuadran IV (Strategi Defensive), maka langkah-langkah yang dilakukan adalah mengurangi kelemahan untuk mengatasi ancaman. Adapun upaya yang peneliti sampaikan disesuaikan dengan faktor-faktor penyebab surging yaitu sebagai berikut:

a. Lolosnya kompresi pada saat pembakaran

Dari hasil observasi dilakukan peneliti adapun upaya yang dilakukan untuk mengatasi masalah tersebut adalah:

1) Penggantian cylinder liner dengan suku cadang yang baru

Cylinder liner yang sudah oversize melebihi toleransi maksimal harus dilakukan penggantian baru agar masalah serupa tidak terulang lagi. di atas kapal MT. Ontari tidak tersedia cylinder liner sejumlah yang dibutuhkan. Hasil pengukuran menunjukan bahwa 5 dari 6 silinder sudah harus diganti karena melebihi batas toleransi. Namun yang terjadi di atas kapal MT. Ontari adalah tidak bisa dilakukan penggantian cylinder liner karena tidak adanya suku cadang, sehingga ditempuh cara alternative untuk mengurangi dampak dari oversize cylinder liner tersebut dengan cara:

a) Menurunkan putaran Mesin Induk

Berdasarkan hasil observasi penurunan putaran Mesin Induk bisa lebih membuat pembakaran lebih stabil karena berada pada putaran yang relatif rendah dan gas buang yang dihasilkan lebih baik daripada menggunakan putaran Mesin Induk maksimal sedangkan gas buang 
yang dihasilkan tidak stabil karena dampak dari lolosnya kompresi dari oversize cylinder liner

b) Mengurangi konsumsi minyak lumas silinder

Berdasarkandari hasil observasi yang dilakukan peneliti, dengan diturunkannya putaran Mesin Induk, maka minyak lumas untuk cylinder liner harus dikurangi agar tidak semakin banyak yang ikut terbakar dan menyumbat groove piston ring yang menyebabkan piston ring macet dan patah. Selain itu pengurangan konsumsi minyak lumas silinder untuk mengurangi sisa kotoran pembakaran yang terkumpul di ruang udara bilas karena dampak dari oversize cylinder liner, sehingga tekanan udara bilas bisa lebih di optimalkan untuk, mensuplai udara pembakaran.

c) Mengoperasikan auxiliary blower secara manual

Berdasarkan hasil observasi, oversize cylinder liner menyebabkan lolosnya kompresi untuk pembakaran sehingga pembakaran yang berlangsung tidak optimal. Sedangkan saat terjadi surging, berdasarkan hasil observasi, wawancara, dan studi pustaka, didapati tekanan udara bilas di bawah 0,8 bar. Untuk tetap dapat mensuplai udara bilas sesuai yang dibutuhkan Mesin Induk agar tidak terjadi surging maka auxiliary blower yang berfungsi untuk membantu suplai udara ke dalam Mesin Induk dioperasikan secara manual. Dengan cara ini auxlliary blower akan terus beroperasi selama Mesin Induk beroperasi untuk mensuplai kekurangan udara akibat lolosnya kompresi dan surging. Namun, harus diperhatikan temperature dari motor auxiliary blower untuk selalu dilakukan pengecekan karena dengan terus beroperasi makan motor akan panas dan menyebabkan motor terbakar.

b. Suplai suku cadang Mesin Induk untuk di atas kapal terhambat

Dari hasil yang dilakukan peneliti, untuk mengatasi masalah tersebut, maka dilakukan langkah-langkah rekondisi suku cadang Mesin Induk. Rekondisi dilakukan pada suku cadang yang masih bisa digunakan atau terhadap suku cadang yang dinilai masih mempunyai kualitas dan kemampuan yang cukup baik. Rekondisi ini dilakukan pada suku cadang seperti piston crown, maupun piston ring yang sering patah dengan cara membersihkan kembali kedua suku cadang 
tersebut untuk dapat digunakan lagi sementara waktu sambil menunggu suku cadang yang baru tiba di atas kapal. Untuk piston ring yang sudah patah tidak bisa lagi digunakan dan sedangkan untuk cylinder liner tidak bisa dilakukan rekondisi karena kondisi yang sudah tidak layak.

\section{KESIMPULAN}

Berdasarkan hasil penelitian yang telah dilakukan Peneliti di kapal MT. Ontari pada tanggal 13 Desember 2016 sampai dengan 4 Januari 2017, dapat disimpulkan bahwa terjadinya surging Mesin Induk Penggerak Utama disebabkan oleh dua sebab, yaitu: 1) Lolosnya kompresi pada saat pembakaran disebabkan oleh oversize cylinder liner yang sudah melebihi batas toleransi maksimal yang berdampak pada bocornya kompresi dan tekanan udara bilas yang turun di bawah normal sehingga menyebabkan pembakaran yang tidak sempurna; 2) Suplai suku cadang Mesin Induk untuk di atas kapal terhambat, sehingga menyulitkan engineer di atas kapal untuk melakukan perawatan dan perbaikan pada Mesin Induk.

Adapun upaya yang dilakukan untuk mengatasi masalah tersebut sesuai dengan hasil penelitian yang peneliti lakukan adalah mengganti cylinder liner yang sudah oversize melebihi batas toleransi maksimal dengan cylinder liner yang baru, menurunkan putaran Mesin Induk agar gas buang lebih stabil, mengurangi konsumsi minyak lumas silinder sehingga tidak banyak minyak lumas yang ikut terbakar dan menjadi lumpur pembakaran di ruang udara bilas, mengoperasikan auxiliary blower menjadi manual agar dapat mensuplai kekurangan tekanan udara bilas dan menjaga tekanan udara bilas dalam tekanan normal selama Mesin Induk beroperasi.

\section{DAFTAR PUSTAKA}

. (2008). Teknik-teknik Analisis Manajemen, Modul Pendidikan dan Pelatihan Kepemimpinan Tingkat III. Lembaga Administrasi Negara: Jakarta.

Endrodi. (2004). Motor Diesel Penggerak Utama. Semarang

Fatimah, Fajar Nur'aini D. (2016). Teknik Analisis SWOT. Quadrant: Yogyakarta.

Mahadi. 2010. Pengaruh Penggunaan Turbocharger dengan Intercooler Terhadap Performansi Motor Bakar Diesel. Jakarta: Jurnal Dinamis. Vol. 1, No.7:23-28. 
Manual Instruction Book For Maintenance and Component Marine Diesel Engine B\&W Type 6L42MC, of MT.Ontari Monthly Report Engine Department Onboard of MT. Ontari. December 2015January 2017.

Narbuko, Chalid dan Abu Achmadi. (2015). Metode Penelitian. PT Bumi Aksara: Jakarta.

Setiawan, Agus. (2016). Pengertian Studi Kepustakaan. Diambil dari: http://www.transiskom.com/2016/03/pengertian-studi-kepustakaan.html, Diakses pada 02 September 2017.

Sugiyono. (2009). Metode Penelitian Kuantitatif, Kualitatif, dan R\&D. CV Alfabeta: Bandung.

Sugiyono. (2016). Metodologi Penelitian Kuantitatif, Kualitatif, dan R\&D. Bandung: CV. Alfabeta.

Sukoco, M.Pd. dan Zainal Arifin,M.T. (2013). Teknologi Motor Diesel. Bandung: Alfabeta.

Woodyard. Doug. (2004). Pounder's Marine Diesel Engine and Gas Turbine. Oxford: Elsevier Butterworth-Heinema. 